\title{
Aggregation of montmorillonite and organic matter in aqueous media containing artificial seawater Yoko Furukawa*1, Janet L Watkins ${ }^{1}$, Jinwook Kim², Kenneth J Curry ${ }^{3}$ and Richard H Bennett ${ }^{4}$
}

Address: ${ }^{1}$ Naval Research Laboratory, Seafloor Sciences Branch, Stennis Space Center, Mississippi, USA, ${ }^{2}$ Yonsei University, Department of Earth System Sciences, Seoul, South Korea, ${ }^{3}$ University of Southern Mississippi, Department of Biological Sciences, Hattiesburg, Mississippi, USA and ${ }^{4}$ SEAPROBE, Inc., Picayune, Mississippi, USA

Email: Yoko Furukawa* - yoko.furukawa@nrlssc.navy.mil; Janet L Watkins - jwatkins@nrlssc.navy.mil; Jinwook Kim - jinwook@yonsei.ac.kr; Kenneth J Curry - kenneth.curry@usm.edu; Richard H Bennett - rhbenn_seaprobe1@bellsouth.net

* Corresponding author

Published: 23 January 2009

Geochemical Transactions 2009, 10:2 doi:10.1/86/1467-4866-10-2
Received: 15 October 2008

Accepted: 23 January 2009

This article is available from: http://www.geochemicaltransactions.com/content/I0/I/2

(c) 2009 Furukawa et al; licensee BioMed Central Ltd.

This is an Open Access article distributed under the terms of the Creative Commons Attribution License (http://creativecommons.org/licenses/by/2.0), which permits unrestricted use, distribution, and reproduction in any medium, provided the original work is properly cited.

\begin{abstract}
Background: The dispersion-aggregation behaviors of suspended colloids in rivers and estuaries are affected by the compositions of suspended materials (i.e., clay minerals vs. organic macromolecules) and salinity. Laboratory experiments were conducted to investigate the dispersion and aggregation mechanisms of suspended particles under simulated river and estuarine conditions. The average hydrodynamic diameters of suspended particles (representing degree of aggregation) and zeta potential (representing the electrokinetic properties of suspended colloids and aggregates) were determined for systems containing suspended montmorillonite, humic acid, and/or chitin at the circumneutral $\mathrm{pH}$ over a range of salinity $(0-7.2 \mathrm{psu})$.

Results: The montmorillonite-only system increased the degree of aggregation with salinity increase, as would be expected for suspended colloids whose dispersion-aggregation behavior is largely controlled by the surface electrostatic properties and van der Waals forces. When montmorillonite is combined with humic acid or chitin, the aggregation of montmorillonite was effectively inhibited. The surface interaction energy model calculations reveal that the steric repulsion, rather than the increase in electronegativity, is the primary cause for the inhibition of aggregation by the addition of humic acid or chitin.

Conclusion: These results help explain the range of dispersion-aggregation behaviors observed in natural river and estuarine systems. It is postulated that the composition of suspended particles, specifically the availability of steric polymers such as those contained in humic acid, determine whether the river suspension is rapidly aggregated and settled or remains dispersed in suspension when it encounters increasingly saline environments of estuaries and oceans.
\end{abstract}

\section{Background}

The dispersion-aggregation behavior of suspended colloids is important to the cycling of matter in rivers and estuaries. For example, the transport and fate of dissolved metal contaminants in rivers and estuarine environments are often directly determined by the potential co-aggregation and sedimentation along with the suspended colloids [1]. Excess nutrients that may be harmful to 
estuarine and coastal ecosystems and fisheries are sometimes removed through the natural processes of aggregation and sedimentation of suspended colloids [2]. The aggregation and dispersion of suspended colloids significantly alters the optical properties of coastal waters and thus a proper interpretation of remote sensing imagery requires the knowledge of the site-specific colloid aggregation-dispersion dynamics [3].

Upon aggregation, river and estuarine colloids are settled to form bottom sediments. The sedimentary aggregates found in estuarine sediments are typically composed of open, porous organo-clay complexes (Figure 1). The essential components of these aggregates are colloidalsized $(<2 \mu \mathrm{m})$ clay mineral particles and colloidal organic matter (organic detritus, living or dead cells, and their degradation and humification products) along with interstitial water and occasional free gas that fills the pore space $[4,5]$. In this report, we use the term "aggregates" to represent units or packets composed of many individual sedimentary colloids and particles. When the context necessitates, these units have sometimes been sub-classified into aggregates, agglomerates, fecal pellets, and flocs, based on the mechanical and/or physicochemical forces that hold the colloids and particles together [6].

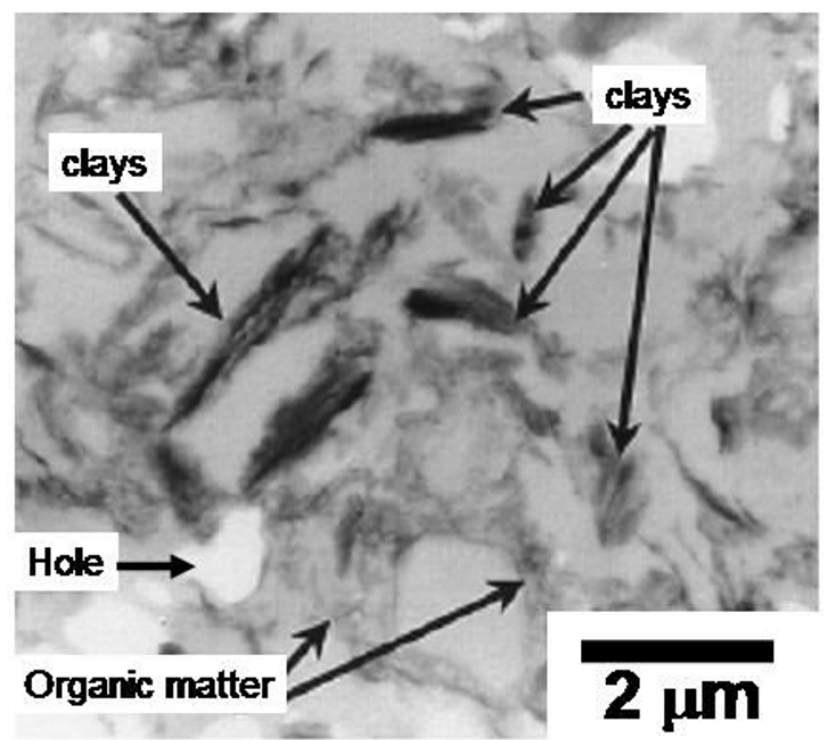

\section{Figure I}

Transmission electron micrograph (TEM) image of resin-embedded, ultrathin-section of fine-grained sediment from the Bay of St. Louis, Mississippi. The fabric is characteristically porous, as the light grey color indicates pore space, now replaced by resin. Dark features represent clay mineral particles (domains) and heavy metalstained organic matter. Bright areas are thin sectioning artifacts (i.e., holes after mineral grains were plucked out during thin-sectioning.)
It has been widely considered that the suspended colloids aggregate due to salinity increase when the river and estuarine waters are mixed with seawater in the vicinity of the river mouths. According to the popular DerjaguinLandau-Verwey-Overbeek (DLVO) Theory, the interaction energy between two similarly charged suspended colloids is determined by the sum of the electrostatic repulsion between the electrical double layers (EDL) at the surface of both particles and van der Waals attraction between the particles. The DLVO theory elucidates the aggregation of suspended colloidal particles, such as hematite and latex colloids, due to increased ionic strength [7]. Increase in electrolyte concentrations allows EDL on the surface of charged colloids to diminish, allowing colloids to come closer and eventually succumb to van der Waals attraction.

The term "physicochemical flocs" has been used in the past to describe the initial formation of clay aggregates within water columns and in the immediate vicinity of sediment-water interface [4,8-10]. A similar physicochemical aggregation behavior has been also observed for iron oxides $[11,12]$. The previous clay studies argue that the open, typically "face-to-edge" association of clay colloids and particles in recent, unconsolidated fine-grained sediments (Figure 2) arises from the electrostatic attraction between negatively charged faces and positively, or at least less negatively, charged edges. The net surface charge of clay mineral particles is a result of two different types of surface charges: (i) permanently negative charge on the basal plane (i.e., "face") due to isomorphic substitution of $\mathrm{Si}$ by $\mathrm{Al}$ in $\mathrm{Si}_{-} \mathrm{O}_{4}$ tetrahedral sheets; and (ii) $\mathrm{pH}$-dependent charge at the "edge" surfaces due to the reversible protonation and deprotonation of the surface hydroxyl groups [13]. The former is independent of $\mathrm{pH}$ and represents > $90 \%$ of the surface charge in the case of montmorillonite due to the platy morphology [14], whereas the latter is $\mathrm{pH}$ dependent. In low $\mathrm{pH}$ (i.e., high proton activity), the latter becomes less negative or even positive according to the reversible protonation and deprotonation reactions of silanol $(\mathrm{Si}-\mathrm{OH})$ and aluminol $(\mathrm{Al}-\mathrm{OH})$ surface groups. The edge surface charges of montmorillonite and kaolinite have been estimated from potentiometric titration to be very close to zero at circumneutral $\mathrm{pH}[15,16]$.

The modified DLVO theory can explain how the attraction increases between negatively charged face surfaces and positively charged or neutral edge surfaces in solutions with higher concentrations of electrolytes (Figure 3) [17]. Essentially, the extended EDL for the negatively charged face surfaces can mask (or spill over on) the neutral or positive charge at edge surfaces in low salinity solutions. In this case the electrostatic force between the face and edge surfaces are repulsion due to their (apparent) negative charge. However in high salinity solutions, the "spill 


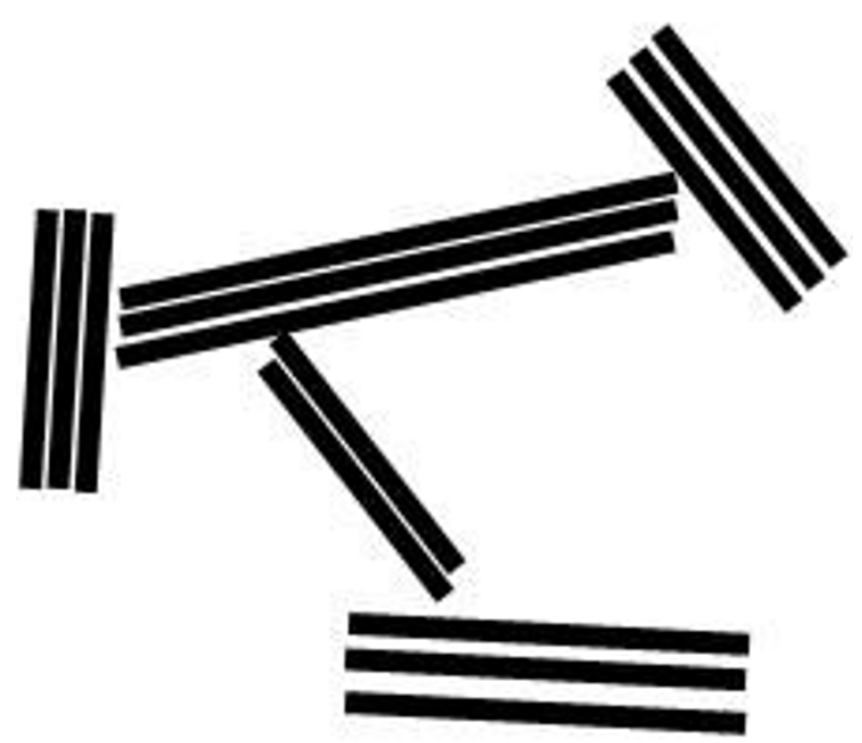

Figure 2

Schematic drawings of a clay aggregate in a face-toedge (F/E) orientation that is ubiquitous in unconsolidated fine-grained sediments. A typical sedimentary clay colloid is composed of several layers of clay unit cells that have sheet-like morphology. (It appears as a stack of rods in this schematic 2D cross section.) Each colloid has large, negatively-charged basal planes (i.e., faces) and less negatively (or positively) charged edges.

over" EDL is diminished and the edge surfaces are more exposed. Electrostatic repulsion is no longer strong, resulting in the face-to-edge arrangement of clay particles that are ubiquitous in fine-grained sediments. The rapid aggregation of river colloids upon salinity increase within estuarine environments, observed in several previous field and laboratory studies [18-21], may be explained by this mechanism.

However, numerous other studies report from environments in which there is little evidence of salinity-induced aggregation in river mouth and estuarine environments. [22-25]. Clearly, there are estuarine systems with suspended colloids in which DLVO-type interactions are not significant [4]. Previous studies show that colloidal suspension of clay minerals and iron oxides that also contain abundant organic matter (OM), especially humic acid (HA), resists aggregation under increased electrolyte concentrations [26-31]. In most cases, the resistance to aggregation has been qualitatively attributed to the adsorption of negatively charged organic polyanions on the clay edge surfaces and resulting strong negative charges on the edges [28,31-33]. The possibility of other repulsive forces (e.g., (a)
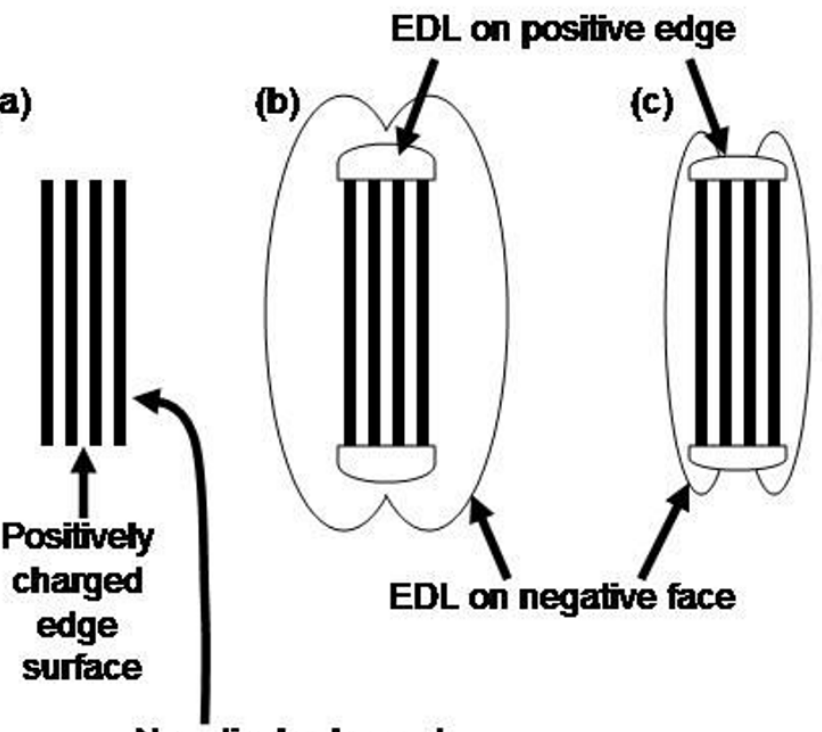

Negatively charged
face surface

Figure 3

Schematic representation of the electrical double layers (EDL) around a clay particle under low and high ionic strength conditions. The $\mathrm{pH}<\mathrm{pH}_{\mathrm{pzc}}$ is

assumed. (a) A model clay particle (domain). (b) Clay particle suspended in a low ionic strength solution. The EDL is comparable to the particle thickness, and as a result, EDL on edge surfaces are masked by EDL on face surfaces. (c) Clay particle suspended in a high ionic strength solution. EDL is relatively thin, and EDL on edge surfaces are exposed. As a result, there is electrostatic attraction between oppositely charged face and edge surfaces. After Tombacz and Szekeres (2006).

steric repulsion) has also been qualitatively alluded [30,33].

Thus, the purpose of this study is to investigate the effect of $\mathrm{OM}$ on the dispersion-aggregation behavior of river suspended colloids using the model organic matter (humic acid and purified chitin) and model clay mineral particles $(<1 \mu \mathrm{m}$ montmorillonite, a common clay mineral type comprising the suite of clay minerals in marine and estuarine fine-grained sediments). The suspension concentrations typically found in OM-rich rivers of temperate regions were studied (i.e., $8 \mathrm{mg} / \mathrm{L}$ clay and up to 4.8 $\mathrm{mg} / \mathrm{L}$ OM suspensions). The results were analyzed quantitatively using the surface interaction energy model based on the DLVO interactions between different model surfaces, in order to quantitatively elucidate the significance of non-DLVO interactions in the dispersion and aggregation of OM-rich colloidal suspensions in estuarine environments. 


\section{Experimental Method Materials and preparation}

Montmorillonite (Ward's Scientific, powdered bentonite, 46E0435), $2 \mathrm{~g}$, was soaked in $1000 \mathrm{~mL}$ distilled water overnight, agitated, and settled for 7 hours and 22 minutes in a settling column. The supernatant in the upper 2.5 $\mathrm{cm}$ of the column containing the size fraction of $<1 \mu \mathrm{m}$ was collected and saved. This process was repeated several times to collect enough material for an adequate suspension. The suspension concentration was checked by drying and weighing a $20 \mathrm{ml}$ aliquot of the homogenized suspension, and then the remainder was adjusted by adding milli-Q water to yield a $16 \mathrm{mg} / \mathrm{L}$ stock suspension. After the addition of milli-Q water, the suspension was stirred for 1 minute before placing an aliquot in the sample cell for size analysis or electrokinetic analysis.

A chitin (Sigma, poly-[1 $\rightarrow 4]-\beta-N$-acetyl-D-glucosamine, purified powder from crab shells, CAS 1398-61-4) sample of $16 \mathrm{mg}$ was dissolved in $1 \mathrm{~L}$ milli-Q water and stirred for 1 hour. Visible sediment formed during the subsequent 1hour settling was removed by filtering through $0.45 \mu \mathrm{m}$ Supor membrane syringe filters. The chitin stock suspension was stored cold, used and discarded within 72 hours.

Humic acid (HA) (Aldrich, Humic acid sodium salt, 60\% humic acid, CAS 68131-04-4) was dissolved in milli-Q water to yield $27 \mathrm{mg} / \mathrm{L}$ stock suspension (or $28 \times 60 \%=$ $16 \mathrm{mg} / \mathrm{L})$. This was stored cold, used and discarded within 72 hours. Before use, the HA suspension was filtered through $0.45 \mu \mathrm{m}$ Supor membrane syringe filters to eliminate possible aggregates formed during storage.

These suspensions are combined so that the final suspension concentrations in experimental runs are $8 \mathrm{mg} / \mathrm{L}$ for montmorillonite, up to $4.8 \mathrm{mg} / \mathrm{L}$ for HA, and $4.8 \mathrm{mg} / \mathrm{L}$ for chitin. These suspension concentrations are within the typical values of material concentrations found in rivers. For example, waters from immediately above the upper estuary of the Pearl River in southern Mississippi has been characterized to contain $30 \pm 20 \mathrm{mg} / \mathrm{L}$ total suspended solids (TSS) [34], with 21 weight \% organic and 79 weight $\%$ inorganic materials (R. H. Stavn, unpublished data).

Artificial seawater (ASW) was prepared by dissolving $23.93 \mathrm{~g} \mathrm{NaCl}, 4.01 \mathrm{~g} \mathrm{Na}_{2} \mathrm{SO}_{4}, 0.67 \mathrm{~g} \mathrm{KCl}, 0.20 \mathrm{~g} \mathrm{NaHCO}_{3}$, $10.83 \mathrm{~g} \mathrm{MgCl}_{2} \cdot 6 \mathrm{H}_{2} \mathrm{O}$, and $1.52 \mathrm{~g} \mathrm{CaCl}_{2} \cdot 2 \mathrm{H}_{2} \mathrm{O}$ to $1 \mathrm{~L}$ milli-Q water (modified after [35]).

\section{Size analysis of suspended particles and aggregates}

The size of suspended particles/colloids and aggregates was investigated by dynamic light scattering spectroscopy (DLS) using a Malvern Zetasizer nano-ZS equipped with MPT-2 titrator at $25^{\circ} \mathrm{C}$. The details of DLS techniques can be found elsewhere [33,36]. Briefly, in DLS measurements, the temporal evolution of the intensity fluctuations of visible light that travels a known distance through an aqueous suspension is used to measure the translational diffusion coefficients of suspended colloids/particles. From the translational diffusion coefficient the average hydrodynamic diameter $\left(d_{H}\right)$ can be determined via the Stokes-Einstein equation. The actual calculations were done using Malvern's DTS ${ }^{\circledR}$ software developed specifically for the Zetasizer.

In reality, the DLS measures the autocorrelation of the temporal fluctuations in the intensity of scattered light due to Brownian motion of the particles and colloids. The measured scatter is expressed as a function of time (i.e., correlation function). The translational diffusion coefficient is obtained from this function using the a fitting method called cumulant analysis $[37,38]$. The materials suspended in this study (i.e., montmorillonite particles/ colloids, OM molecules, as well as their aggregates) are not spherical. Consequently, the $d_{H}$ values measured in this study are considered to be a measure of the relative sizes under given experimental conditions. In addition, it should also be noted that the materials vary in size due to the range of sizes in individual particles/colloids as well as the size variation due to aggregation. Consequently, the $d_{H}$ values reported in this study are the average hydrodynamic diameter. Whereas inversion methods (e.g., CONTIN) are often used in polydispersed systems to obtain the size distribution as well as average $d_{H}$ from the correlation function, the complexity of highly polydispersed natural systems with non-spherical particles make the application of inversion methods impractical. Thus the cumulant method was used in this study [37].

The $d_{H}$ values reported in this study are based on the size distribution by scatter intensity, rather than on the size distributions by volume or by the number of discrete particles [39]. The scattering intensity of a particle is proportional to the particle size to the sixth power. Consequently, the $d_{H}$ values reported here are a robust mean to compare the size differences of larger particles and aggregates, while being insensitive to the possible contributions from smaller particles that occupy less than $50 \%$ of the suspended material mass.

The DLS has been used successfully in previous laboratory studies to characterize the $d_{H}$ values of clay colloid and aggregate suspensions $[28,33]$ as well as the that of HA macromolecules suspended/dissolved in aqueous media $[37,40,41]$. It should be noted that, even though the individual macromolecules of dissolved HA is very small (i.e., $d_{H} \approx 3 \mathrm{~nm}$, [42]) approaching the lower resolution limit of the DLS analysis by Malvern Zetasizer nano ZS (i.e., $d_{H}>$ 
$0.6 \mathrm{~nm},[39])$, they usually take the form of aggregates, or supramolecules, in aqueous suspensions. The supramolecules are typically reported to be in the range of $d_{H}=8-$ $450 \mathrm{~nm}$ with the average $d_{H}$ values in the order of a few to several hundred nanometers $[40,41]$.

The size analyses were conducted separately for montmorillonite-only suspension, chitin-only suspension, HAonly suspensions, montmorillonite plus chitin suspensions, and montmorillonite plus HA suspensions.

The effect of salinity on the sizes of suspended colloids/ particles and aggregates were determined by tracking the time-dependent evolution of $d_{H}$ values following the mixing of ASW with the clay (+/- OM) suspensions using DSL. Prior to each analysis, the $\mathrm{pH}$ value was adjusted to 7.2 with a small amount of $0.1 \mathrm{~N} \mathrm{NaOH}$ or $\mathrm{HCl}$. After mixing with ASW, the mixed aqueous solution was continuously stirred. Every 3 - 5 minutes, the mixed aqueous solution was introduced to the Zetasizer sample cell with the circulation system integrated into the MPT-2 titrator for the DLS analysis.

\section{Zeta potential analysis of suspended particles and aggregates}

Zeta potential is an electrokinetic property of the EDL surrounding the particle. It is a potential at the slip plane that divides the diffuse layer into two regions: the inner diffuse layer where ions move with the particle movement, and outer diffuse layer where ions are still influenced by the particle due to long range forces but are not part of the coherent unit that moves with the particle. Even though the $\zeta$-potential is defined as such and is strictly different from the surface potential, it is often used as a proxy for the surface potential as: (i) it represents the average electrokinetic behavior of the particles; and (ii) it can be determined experimentally unlike the surface potential.

The analysis of $\zeta$-potential as a function of $\mathrm{pH}$ at a range of discrete salinity values were conducted by laser Doppler velocimetry (LDV) using a Malvern Zetasizer nano-ZS equipped with a MPT-2 titrator at $25^{\circ} \mathrm{C}$. Each suspension sample, with an appropriate adjustment to $\mathrm{pH}$ and salinity, was loaded into a capillary cell with embedded electrodes at either of the two ends using the titrator. Suspended particles moved towards the electrode of the opposite charge when the potential was applied, and their velocity was measured and expressed in the unit field strength as their mobility. By knowing the physical properties of the suspension medium, the velocity can be converted to the $\zeta$-potential using the Smolchowski equation [38]. The LDV techniques have been previously used to characterize the $\zeta$-potentials of clays [43] and HA [44].

\section{Results}

Particle aggregation in montmorillonite plus OM systems The average $d_{H}$ values of pure montmorillonite, HA, and chitin suspensions, without salinity increase, were determined by DLS to be $211( \pm 50), 181( \pm 23)$, and $269( \pm$ 31) $\mathrm{nm}$, respectively.

Montmorillonite colloids in montmorillonite-only suspension form aggregates in constantly stirred solutions with elevated salinity (Figure 4). In zero salinity solutions, the value of $d_{H}$ remains at approximately $200 \mathrm{~nm}$ throughout the first 60 minutes after mixing with ASW. In systems with ASW (i.e., $S=1.8$, 3.6, and 7.2 psu), the DLS analysis detected increase in the value of the average hydrodynamic diameter $\left(d_{H}\right)$ which indicates the formation of aggregates. This result agrees with the previous studies of laboratory kaolinite and montmorillonite aggregation in which the dispersion-aggregation properties of pure clay suspensions were found to be primarily determined by the solution ionic strengths (See Figure 3, also [29,45]). This is the behavior expected from suspensions whose dispersion-aggregation behaviors are primarily governed by the DLVO behaviors of competing electrostatic repulsion and van der Waals attraction.

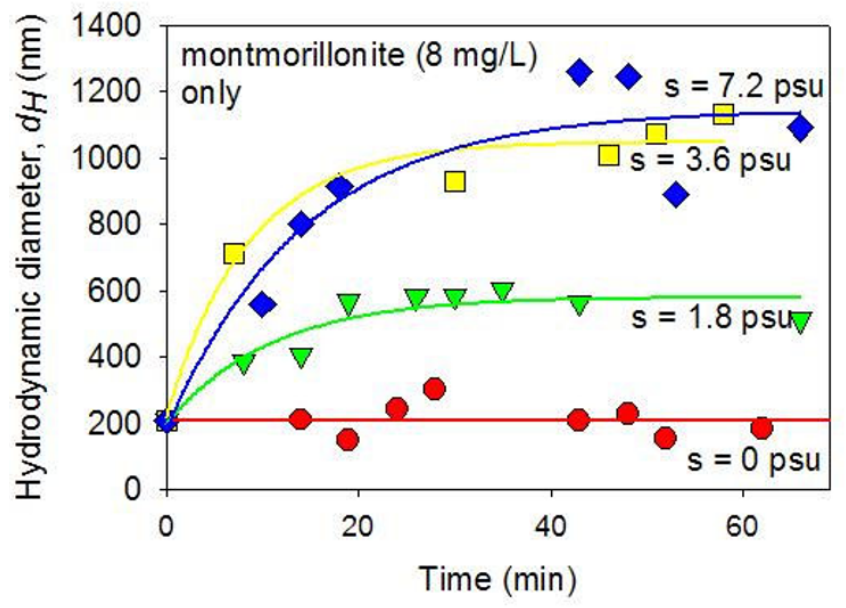

Figure 4

Average hydrodynamic diameters $(\mathrm{dH})$ of montmorillonite-only suspensions $(8 \mathrm{mg} / \mathrm{L})$ in constantly stirred solutions were measured as a function of time after mixing with artificial seawater (ASW) using dynamic light spectroscopy. The $\mathrm{pH}$ was circumneutral. The results show a lack of aggregation in the zero salinity suspension. On the other hand, at elevated salinity values, ( $S$ $=1.8-7.2 \mathrm{psu}$ ), the colloidal particles rapidly aggregate during the initial 15 minutes following the ASW mixing. In the $S$ $=1.8$ psu suspension, the aggregates reach the steady state average size of $d H \approx 600 \mathrm{~nm}$ after 20 minutes. In the $S=3.6$ and $S=7.2$ psu suspensions, the aggregates become larger $(d H \approx I, 100 \mathrm{~nm})$ after the initial rapid aggregation. 
The colloidal suspensions in montmorillonite + HA systems did not aggregate as much as the montmorilloniteonly suspensions upon mixing with ASW (Figures 5 and $6)$. With a small amount of HA $(1.6 \mathrm{mg} / \mathrm{L})$, the aggregation in $\mathrm{S}=1.8$ and 3.6 psu suspensions were trivial (Figure $5)$. With more HA $(4.8 \mathrm{mg} / \mathrm{L})$, no time-dependent aggregation was detected in $S=1.8$ and 3.6 psu suspensions (Figure 6$)$. With a higher salinity value $(S=7.2 \mathrm{psu})$, the mixed montmorillonite + HA suspensions went through some degree of time-dependent aggregation. However, the rate of aggregation was significantly slower than the rate of aggregation observed in the system with no HA (Figures $4,5,6$ ). These results agree with the previous studies in which the salinity-induced aggregation of clays were hindered by the addition of HA [27]. It has been argued that the HA is adsorbed on the clay edge surfaces due to the surface complexation between clay aluminol and HA carboxyl groups $[28,46]$. This increases the dispersion by: (1) the increased negativity (or even charge reversal from positive to negative) at the clay edge surfaces (and thus increased electrostatic repulsion); and (2) steric repulsion due to polymeric components of HA $[27,32,33]$.

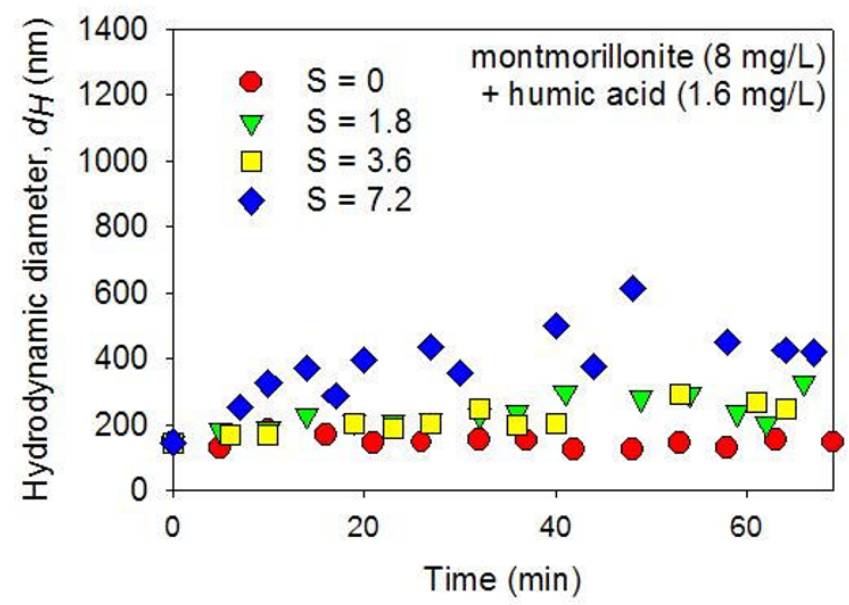

Figure 5

Average hydrodynamic diameters $(\mathrm{dH})$ of montmorillonite ( $8 \mathrm{mg} / \mathrm{L})$ + HA ( $1.6 \mathrm{mg} / \mathrm{L})$ suspensions in constantly stirred solutions were measured as a function of time after mixing with artificial seawater (ASW) using dynamic light spectroscopy. The $\mathrm{pH}$ was circumneutral. The results show a lack of aggregation in the zero salinity suspension. In the suspensions with slightly elevated salinity (i.e., $\mathrm{S}=1.8$ and $3.6 \mathrm{psu}$ ), a slight increase in the average $d H$ was detected toward the end of the time series observations ( $T \approx 60$ minutes). At the highest salinity value investigated ( $S=7.2 \mathrm{psu}$ ), the colloidal particles gradually aggregated during the $\sim 60$ minutes following the ASW mixing.

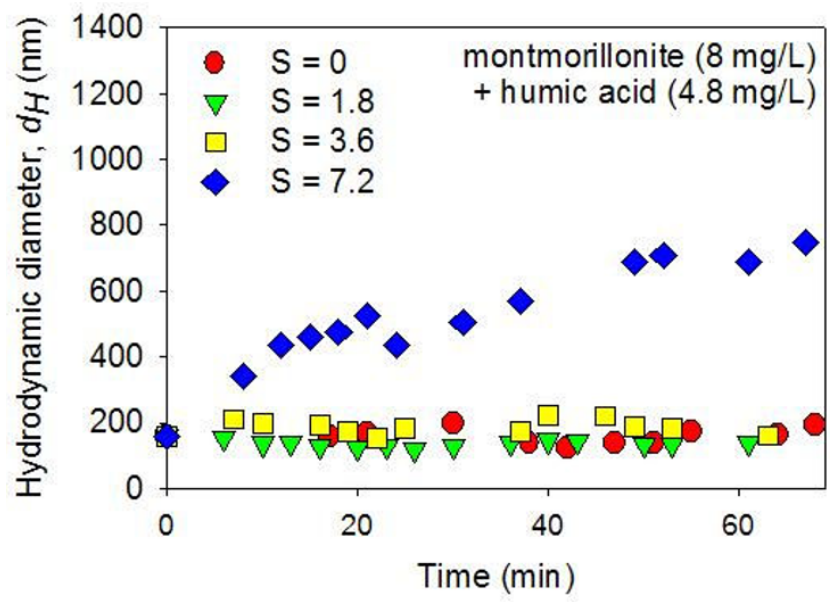

Figure 6

Average hydrodynamic diameters $(\mathrm{dH})$ of montmorillonite $(8 \mathrm{mg} / \mathrm{L})+\mathrm{HA}(4.8 \mathrm{mg} / \mathrm{L})$ suspensions in constantly stirred solutions were measured as a function of time after mixing with artificial seawater (ASW) using dynamic light spectroscopy. The $\mathrm{pH}$ was circumneutral. The results show a lack of aggregation in the zero salinity suspension. In addition, no time-dependent aggregation was detected in suspensions with elevated salinity (i.e., $S$ $=1.8$ and $3.6 \mathrm{psu}$ ). At the highest salinity value investigated (S $=7.2 \mathrm{psu}$ ), the colloidal particles gradually aggregated during the $\sim 60$ minutes following the ASW mixing.

The colloidal suspensions in montmorillonite + chitin systems did not aggregate as much as the montmorillonite-only suspensions (Figures 7$)$. With chitin $(4.8 \mathrm{mg} / \mathrm{L})$, very little, if any, time-dependent aggregation was detected in $S=1.8$ and 3.6 psu suspensions. With a higher salinity value ( $S=7.2 \mathrm{psu}$ ), the mixed montmorillonite + chitin suspensions went through some amount of timedependent aggregation. However, the rate of aggregation was much slower than the rate of aggregation observed in the system with no chitin (Figures 4 and 7).

The results can be summarized as follows. (1) Montmorillonite-only suspension aggregates with increasing salinity, as expected from DLVO Theory: the system's dispersion-aggregation characteristics are primarily governed by the balance between electrostatic repulsion and van der Waals attraction. (2) The DLVO-driven aggregation of montmorillonite is inhibited by the addition of HA or chitin. The magnitude of inhibition is a function of salinity.

\section{Zeta potential of organic matter and aggregation behaviors}

The $\zeta$-potential of chitin as a function of $\mathrm{pH}$ at low salinity values $(S \approx 1.1-2.1)$ characterizes suspended chitin as particles with little electrostatic charges (Figure 8). This 


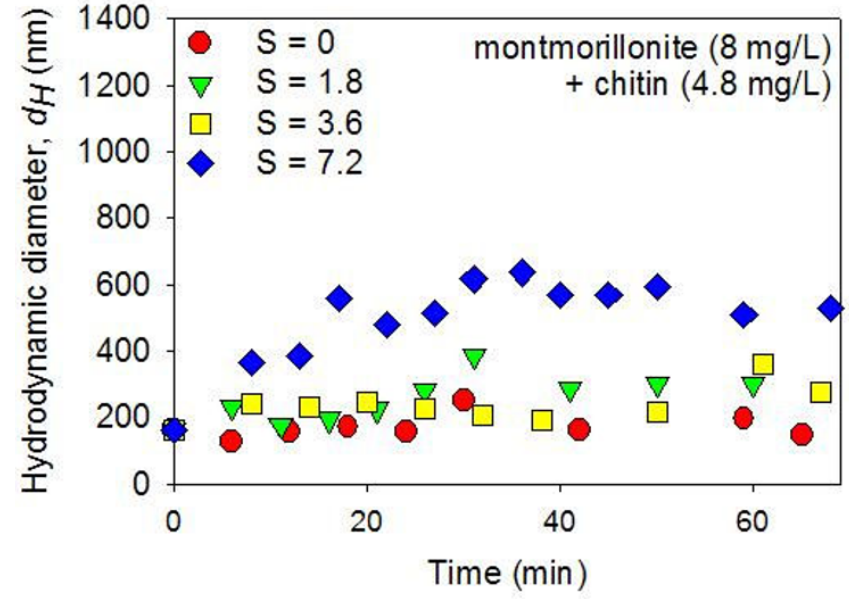

Figure 7

Average hydrodynamic diameters $(\mathrm{dH})$ of montmorillonite $(8 \mathrm{mg} / \mathrm{L})+$ chitin $(4.8 \mathrm{mg} / \mathrm{L})$ suspensions in constantly stirred solutions were measured as a function of time after mixing with artificial seawater (ASW) using dynamic light spectroscopy. The $\mathrm{pH}$ was circumneutral. The results show a lack of aggregation in the zero salinity suspension. In addition, very little time-dependent aggregation was detected in suspensions with elevated salinity (i.e., $\mathrm{S}=\mathrm{I} .8$ and $3.6 \mathrm{psu}$ ). At the highest salinity value investigated ( $S=7.2 \mathrm{psu}$ ), the colloidal particles gradually aggregated during the $\sim 60$ minutes following the ASW mixing.

characterization comes from the near-zero $\zeta$-potential values that are virtually independent of $\mathrm{pH}$ in aqueous solutions. The data in Figure 8 also reveal the $\mathrm{pH}$-dependent surface charge in the zero salinity chitin suspension. This charge is derived from the protonation of the amino group at low $\mathrm{pH}$ and deprotonation of the hydroxyl group at high $\mathrm{pH}$.

The $\zeta$-potential of HA molecules as a function of $\mathrm{pH}$ at two different salinity values characterizes humic acid as negatively charged colloids (Figure 9). This negative charge is primarily due to phenolic and carboxylic functional groups. The increase in salinity decreases the negative $\zeta$-potential value to a certain degree, as would be expected from the availability of counter-ions.

The $\zeta$-potential values of pure montmorillonite, HA, and chitin suspensions as a function of salinity (Figure 10) reveal that the $\zeta$-potential is a very strong function of salinity in very low salinity suspensions $(S \approx 0-2 \mathrm{psu})$ with less salinity dependency at higher salinity ( $>2$ psu).

\section{Discussion}

Previous studies of clay-OM interactions in the context of dispersion and aggregation mostly focused on the role of

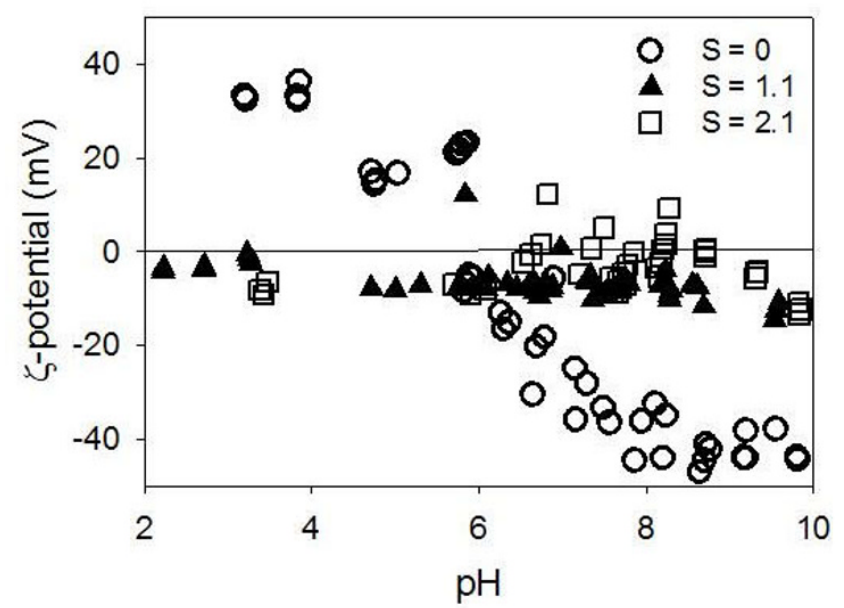

Figure 8

The $\zeta$-potential of chitin suspension as a function of pH at three discrete salinity values. At zero salinity, zpotential is a function of $\mathrm{pH}$, with the point of zero charge at approximately $\mathrm{pH}_{\mathrm{pzc}}=5.5$. However, when a small amount of electrolyte is present in the system, $\zeta$-potential immediately becomes insensitive to $\mathrm{pH}$, with its value very close to zero.

OM in modifying the surface electrostatic properties of the clays [27-29,33,45]. They showed that the adsorption of OM on clay surfaces, primarily through surface complexation between clay edge aluminol and OM's acidic functional groups, increased the electronegativity of the clay

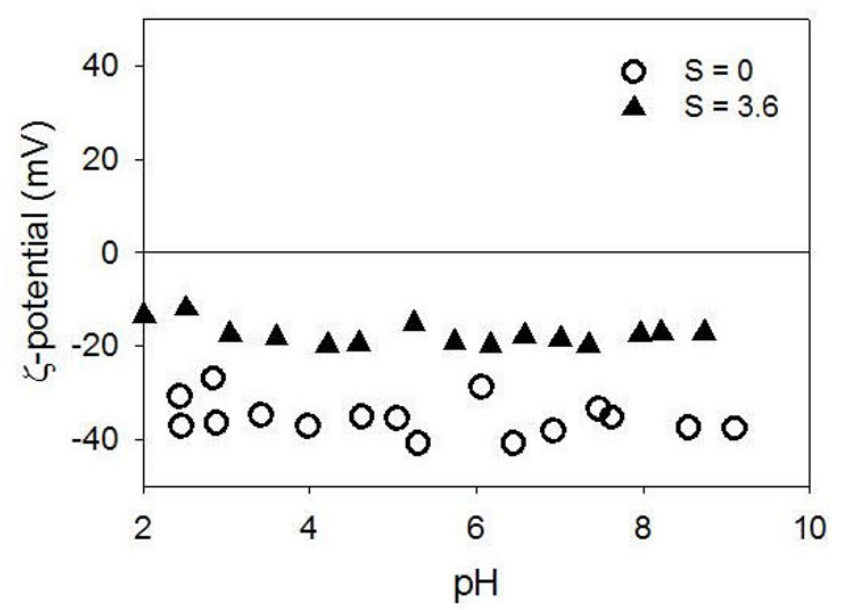

Figure 9

The $\zeta$-potential of humic acid (HA) suspension as a function of $\mathrm{pH}$ at two discrete salinity values. At zero salinity, $\zeta$-potential is independent of $\mathrm{pH}$ and highly negative, indicative of electrostatically stable colloidal suspension. At a higher salinity, $\zeta$-potential is less negative but still at $\Phi_{Z} \approx-20$ $\mathrm{mV}$. 


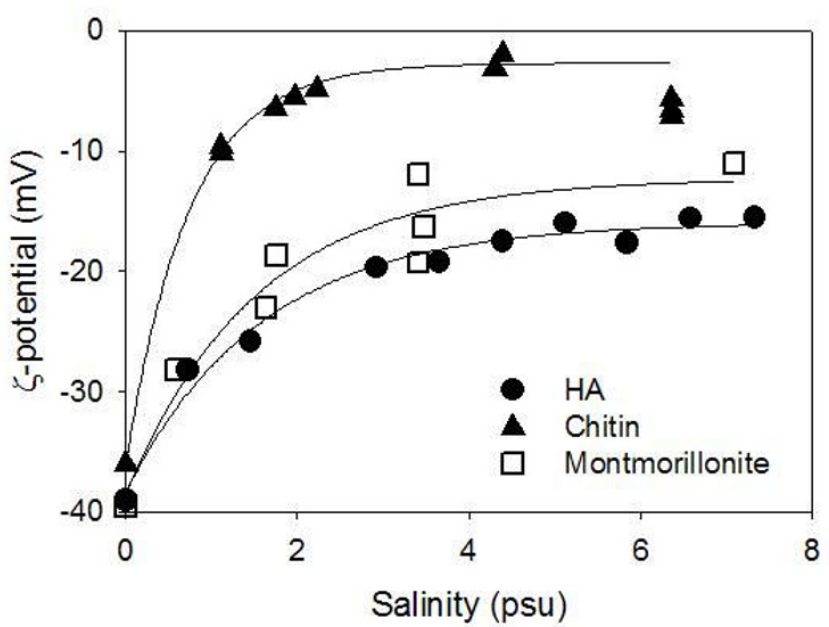

Figure 10

The $\zeta$-potential of humic acid (HA), chitin and montmorillonite suspensions at circumneutral $\mathbf{~ H ~}$ (7 $<\mathrm{pH}<7.5)$ as a function of salinity. Note that the value for montmorillonite are averages over different surfaces including permanently negative face surfaces and less negative (and neutral or even positive in low $\mathrm{pH}$ ) edge surfaces.

surfaces, resulting in increased electrostatic repulsion. The presence of steric repulsion has been qualitatively mentioned, but has not been explicitly quantified. We used the surface interaction energy model to calculate the contribution of electrostatic repulsion and van der Waals attraction to the observed dispersion-aggregation behaviors, in order to estimate quantitatively the magnitude of other repulsive forces (e.g., steric repulsion).

Particle interaction in a system that contains montmorillonite particles with OM adsorption on edge surfaces is controlled partly by electrostatic and Lifshitz-van der Waals contributions, as well as steric repulsion of OM polymers [29]. The relative magnitudes of these contributions determine whether the particles aggregate or remain dispersed and suspended in solution.

One mechanism for the montmorillonite dispersion is the electrostatic repulsion [29]. The bare montmorillonite edges are nearly neutrally charged in contrast to the negatively charged face surfaces. This surface charge difference leads to the likelihood of face-to-edge aggregation upon increased salinity (and thus diminished "spillover" EDL) (Figure 3). However, once HA molecules are adsorbed onto the edge surfaces, the HA-covered surface will become negatively charged, even in solutions with modest electrolyte concentrations. This would prevent the edge-to-face aggregation from occurring easily. Chitin does not have the same electrostatic effect as it is very close to neutrally charged in suspensions with any amount of electrolytes (Figures 8 and 10). If no other forces (i.e., steric repulsion) are present, these electrostatic repulsive forces need to overcome Lifshitz-van der Waals attractive forces if the particles are to remain in suspension as we observed in this study.

The electrostatic interaction energy between phases $i$ and $j$ in aqueous medium per unit area, $V_{i j}^{E L}$, is calculated using the Hogg, Healy and Fuerstenau (HHF) model [47], based on the assumption of constant, moderate surface potentials on two infinite flat planes. It should be noted that this model is appropriate when surface-to-surface distance $H$ satisfies $H \geq 10 \mathrm{~nm}$.

$$
V_{i j}^{E L}=\frac{\varepsilon \varepsilon_{0} \kappa}{8 \pi}\left[\left(\psi_{0 i}^{2}+\psi_{0 j}^{2}\right)(1-\operatorname{coth} \kappa H)+2 \psi_{0 i} \psi_{0 j} \cos e c h \kappa H\right]
$$

[48]. Here $\varepsilon$ is the dielectric constant of the medium ( $\varepsilon=$ 78.4 for aqueous medium at $25^{\circ} \mathrm{C}$ ), $\varepsilon_{0}$ is the permittivity in vacuum, $\kappa$ is the reciprocal Debye length which is a function of ionic strength $I$ (i.e., $\left.\kappa=\frac{\sqrt{I}}{0.3082}\left(\mathrm{~nm}^{-1}\right)\right)$, and subscripts $(i, j)$ represent different surfaces (e.g., $f$ for montmorillonite face, $c$ for chitin-covered edge, and ha for HA-covered edge). The surface potential of phase $i, \psi_{0 i}$ can be reasonably approximated by the zeta potential, $\psi_{z i}$ $(\mathrm{mV})$.

In the following calculations, the $\zeta$-potentials of chitinand HA-covered edges, $\psi_{z c}$ and $\psi_{z h a}$, were estimated to be equal to that of free-suspending chitin and HA that were determined experimentally for circumneutral $\mathrm{pH}$ as described above and shown in Figure 10 as a function of salinity. The data were modeled using the exponential rise function as functions of salinity $(S, \mathrm{psu})$ as follows:

$$
\begin{aligned}
\psi_{z c} & =-36.0+33.3\left(1-e^{-1.36 S}\right)(\mathrm{mV}) \\
\psi_{z h a} & =-38.2+22.3\left(1-e^{-0.626 S}\right)(\mathrm{mV})
\end{aligned}
$$

The $\zeta$-potential of the montmorillonite face surface, $\psi_{z f}$ was assumed to be equal to the bulk $\zeta$-potential of the montmorillonite suspension because the edge surface represents only a small fraction $(<1 \%)$ of the net surface area [48]. It is reported in Figure 10 for circumneutral $\mathrm{pH}$, and the data were modeled as follows:

$$
\psi_{z f}=-38.5+26.3\left(1-e^{-0.655 S}\right)(\mathrm{mV})
$$


The Lifshitz-van der Waals contribution, $V_{i j}^{L W}$, was calculated using the following equation [48]:

$$
V_{i j}^{L W}=-\frac{A_{i j}}{12 \pi H^{2}}
$$

where $A_{i j}$ is the Hamaker constant corresponding to the van der Waals interaction between phases $i$ and $j$ in aqueous medium. In this case, we assume that the van der Waals interaction between the montmorillonite face and the OM-coated edge surfaces is similar to that between the
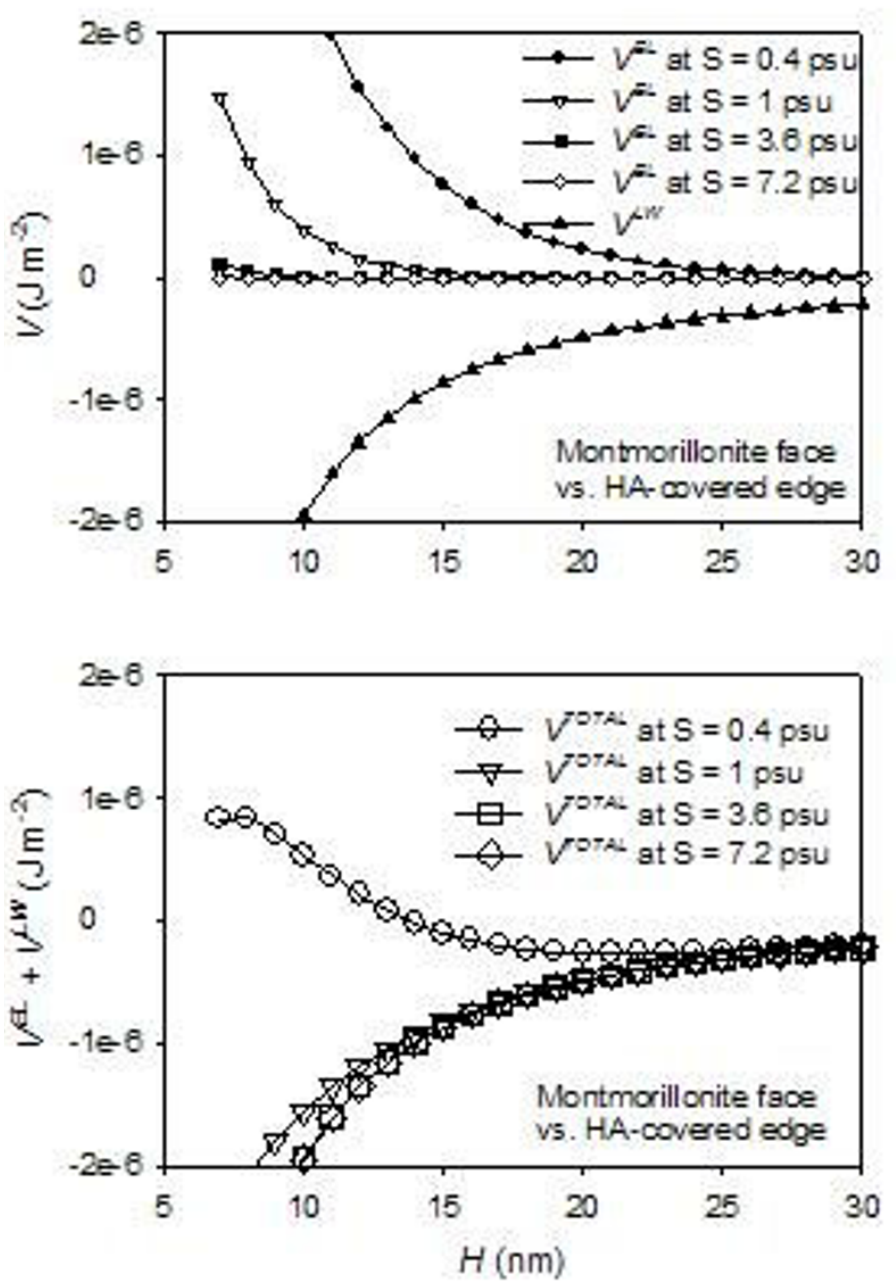

montmorillonite face and the bare edge, and thus the value of $A_{i j}$ was taken from the literature to be $A_{f e}=7.3 \times$ $10^{-21} \mathrm{~J}[48]$.

The values of $V_{i j}^{E L}$ and $V_{i j}^{L W}$, as well as $V_{i j}^{E L}+V_{i j}^{L W}$ were calculated for certain discrete salinity values (i.e., $S=0.3$, $1,3.6$, and $7.2 \mathrm{psu}$ ) using the $\zeta$-potential values experimentally determined and interpolated at circumneutral pH (Figure 10), and shown in Figure 11. These results show that the sum of electrostatic and Lifshitz-van der Waals forces is constantly negative under the experimental
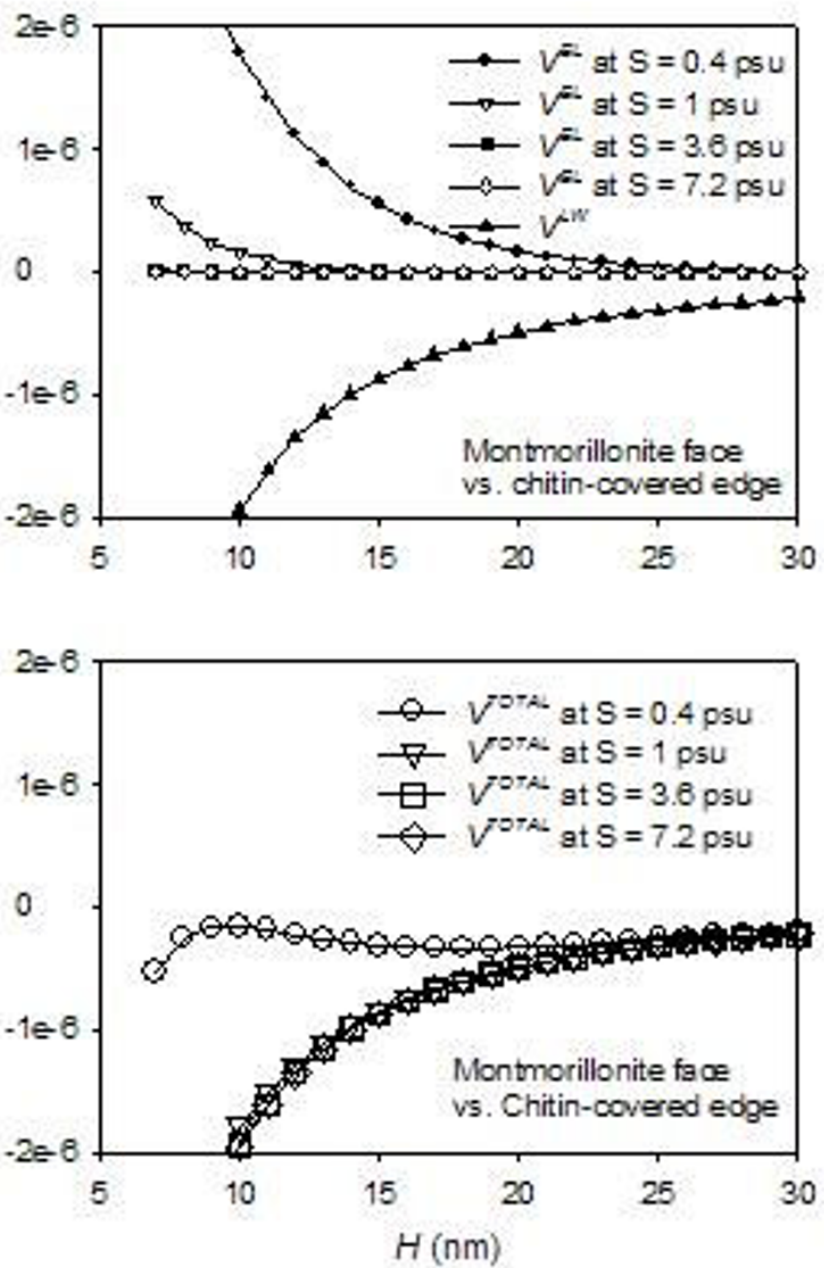

\section{Figure I I}

Surface interaction energy calculated from electrostatic interaction (VEL) (i.e., Equation I) and Lifshitz-van der Waals interaction (VLW)(i.e., Equation 5). The $V E L$ and $V L W$ values are shown individually in the upper figures, whereas the net energy values are shown in the lower figures. The net sum of $V E L$ and $V L W$ remains negative throughout the experimental conditions used to derive the z-potential (i.e., circumneutral $\mathrm{pH}$ at salinity values indicated on figure) except for the interaction between face and HA-covered edge at very low salinity $(S=0.4 \mathrm{psu})$. Net negative surface interaction energy would induce aggregation, whereas our observations yielded very little aggregation for $S=3.6$ psu and below. On the other hand, aggregation was observed at $S=7.2$ psu. 
conditions we considered, except for the HA system with very low salinity ( $\mathrm{S}=0.4 \mathrm{psu}$ ). This negative interaction energy would cause particles to approach each other and aggregate. However, montmorillonite did not aggregate in the HA-containing systems at $\mathrm{S}<3.6 \mathrm{psu}$. Meanwhile, aggregation was observed at $S=7.2$. Consequently, it is clear that other repulsive forces, such as steric repulsion, are quantitatively important in these systems in order to keep particles well dispersed in suspensions with $S=3.6$ psu or less.

The magnitude of steric repulsion can be estimated by comparing the values of $V^{T O T A L}\left(=V^{E L}+V^{L W}\right)$ at $S=3.6$ and $7.2 \mathrm{psu}$. At $\mathrm{S}=3.6 \mathrm{psu}$, the steric repulsion was at least as significant as the negative values of $V^{T O T A L}$ in order to keep the colloids dispersed. On the other hand, at $S=7.2 \mathrm{psu}$, the steric repulsion was exceeded by the negative values of $V^{T O T A L}$. It should be noted that the range estimation is conducted under the assumption that the steric repulsion is independent of salinity; thus the range is a rough estimate. In reality, the hydrodynamic diameters of polymers are greater in higher salinity solution due to the polymer unfolding, and thus the steric repulsive forces may be greater in higher salinity solutions [49]. Figure 12 shows the estimated ranges for the magnitude of the additional repulsion (i.e., steric repulsion) $V^{S T}$ for the montmorillonite-HA suspensions determined by bracketing with $V^{\text {TO- }}$ ${ }^{T A L}$ at $\mathrm{S}=3.6$ and $V^{T O T A L}$ at $\mathrm{S}=7.2 \mathrm{psu}$. The estimate for montmorillonite-chitin suspensions is not shown but very similar. The $V^{S T}$ values are quantitatively significant, as their values, even though rough estimates, are in the same order of magnitudes as the van der Waals attraction.

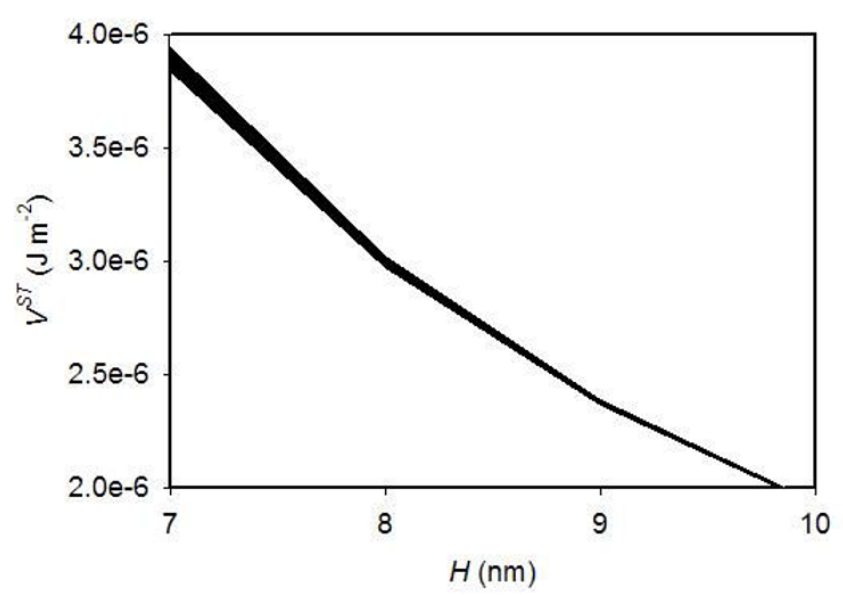

Figure 12

The estimated range for the magnitude of repulsive forces operating in the montmorillonite-HA suspensions is indicated by the black band.

\section{Conclusion}

Rivers erode rocks and soils, and carry the mineral particles, especially fine-grained clay mineral particles, down to the estuarine environments. The fate of these particles, whether they are aggregated and settled rapidly or dispersed and remain in suspension for prolonged period of time for further hydrodynamic transport, is significantly influenced by the amount of organic matter that is also suspended in the river water.

Our experimental results indicate that organic macromolecules, which are a major component of many riverine suspensions in general, prevents clay mineral aggregation through (1) augmentation of the electrostatic repulsion between the face and edge surfaces of clay minerals by rapidly adsorbing onto the edge surface and increasing its negative charge; and (2) introduction of steric repulsion. The surface interaction energy calculations indicate that the latter (i.e., steric repulsion) is quantitatively more significant than the augmentation of electrostatic repulsion.

\section{Competing interests}

The authors declare that they have no competing interests.

\section{Authors' contributions}

All authors contributed to the design of the experiments and manuscript draft. YF conceived the study, designed the specific details of the experiments, conducted the interaction energy calculations, and drafted the initial manuscript. JLW carried out the Zetasizer experiments. JK, $\mathrm{KJC}$, and RHB conducted electron microscopy analyses (not reported here) that guided the course of Zetasizer experiments. All authors read and approved the manuscript.

\section{Acknowledgements}

This study was funded by ONR/NRL Core 6.I funding (PE\#060 I I53N). We also acknowledge partial support of NSF OCE- 0824569 for KJC and partial support of NSF OCE- 0824566 for RHB. NRL Contribution JA/7430-08-2. NRL Contribution JA/7430-08-XX.

\section{References}

I. SanudoWilhelmy SA, RiveraDuarte I, Flegal AR: Distribution of colloidal trace metals in the San Francisco Bay estuary. Geochimica et Cosmochimica Acta 1996, 60:4933-4944.

2. Eyre B, Twigg C: Nutrient behaviour during post-flood recovery of the Richmond River Estuary Northern NSW, Australia. Estuarine Coastal and Shelf Science 1997, 44:3II-326.

3. Stramski $D$, Boss $E$, Bogucki $D$, Voss $K J$ : The role of seawater constituents in light backscattering in the ocean. Progress in Oceanography 2004, 61:27-56.

4. Bennett RH, O'Brien NR, Hulbert MH: Determinants of Clay and Shale Microfabric Signatures: Processes and Mechanisms. In Microstructure of Fine-Grained Sediments: From Mud to Shale Edited by: Bennett RH, Bryant WR, Hulbert MH. Springer-Verlag; 1991:582.

5. Curry KJ, Bennett RH, Mayer LM, Curry A, Abril M, Biesiot PM, Hulbert $\mathrm{MH}$ : Direct visualization of clay microfabric signatures driving organic matter preservation in fine-grained sediment. Geochimica et Cosmochimica Acta 2007, 71:1709-1720.

6. Syvitski JPM: The changing microfabric of suspended particulate matter - The fluvial to marine transition: Flocculation, 
agglomeration, and pelletization. In Microstruccture of Finegrained Sediments Edited by: Bennett RH, Bryant WR, Hulbert MH. Springer-Verlag: New York; 1991:131-137.

7. Behrens $\mathrm{SH}$, Borkovec $\mathrm{M}$, Schurtenberger $\mathrm{P}$ : Aggregation in charge-stabilized colloidal suspensions revisited. Langmuir 1998, I 4:1951-1954.

8. Reynolds S, Gorsline DS: Clay Microfabric of Deep-Sea, Detrital Mud(Stone)S, California Continental Borderland. Journal of Sedimentary Petrology 1992, 62:41-53.

9. Collins K, McGown A: Form and Function of Microfabric Features in a Variety of Natural Soils. Geotechnique 1974, 24:223-254.

10. Hein FJ: Fine-Grained Slope and Basin Deposits, California Continental Borderland - Facies, Depositional Mechanisms and Geotechnical Properties. Marine Geology 1985, 67:237-262.

I I. Tipping E, Ohnstad M: Colloid Stability of Iron-Oxide Particles from a Fresh-Water Lake. Nature 1984, 308:266-268.

12. Amal R, Coury JR, Raper JA, Walsh WP, Waite TD: Structure and Kinetics of Aggregating Colloidal Hematite. Colloids and Surfaces 1990, 46:1-19.

13. Kraepiel AML, Keller K, Morel FMM: A model for metal adsorption on montmorillonite. Journal of Colloid and Interface Science 1999, 21 0:43-54.

14. Zarzycki P, Szabelski P, Piasecki W: Modelling of zeta-potential of the montmorillonite/electrolyte solution interface. Applied Surface Science 2007, 253:579I-5796.

15. Nagy NM, Konya J: The adsorption of valine on cationexchanged montmorillonites. Applied Clay Science 2004, 25:57-69.

16. Huertas FJ, Chou L, Wollast R: Mechanism of kaolinite dissolution at room temperature and pressure: Part I. Surface speciation. Geochimica et Cosmochimica Acta 1998, 62:417-431.

17. Tombacz E, Szekeres M: Surface charge heterogeneity of kaolinite in aqueous suspension in comparison with montmorillonite. Applied Clay Science 2006, 34: I05-I24.

18. Forsgren G, Jansson M, Nilsson P: Aggregation and sedimentation of iron, phosphorus and organic carbon in experimenta mixtures of freshwater and estuarine water. Estuarine Coastal and Shelf Science 1996, 43:259-268.

19. Ouddane B, Skiker M, Fischer JC, Wartel M: Distribution of iron and manganese in the Seine river estuary: approach with experimental laboratory mixing. Journal of Environmental Monitoring 1999, I:489-496.

20. Zajaczkowski M: Sediment supply and fluxes in glacial and outwash fjords, Kongsfjorden and Adventfjorden, Svalbard. Polish Polar Research 2008, 29:59-72.

21. Sholkovitz ER: Flocculation of Dissolved Organic and Inorganic Matter During Mixing of River Water and Seawater. Geochimica et Cosmochimica Acta 1976, 40:831-845.

22. Eisma D, Bernard P, Cadee GC, Ittekkot V, Kalf J, Laane R, Martin JM, Mook WG, Vanput A, Schuhmacher T: Suspended-Matter Particle-Size in Some West-European Estuaries .I. Particle-Size Distribution. Netherlands Journal of Sea Research 1991, 28:193-214.

23. Thill A, Moustier S, Garnier JM, Estournel C, Naudin JJ, Bottero JY: Evolution of particle size and concentration in the Rhone river mixing zone: influence of salt flocculation. Continental Shelf Research 2001, 2 I:2 I 27-2 I40.

24. Berhane I, Sternberg RW, Kineke GC, Milligan TG, Kranck K: The variability of suspended aggregates on the Amazon Continental Shelf. Continental Shelf Research 1997, I 7:267-285.

25. Eisma D: Flocculation and De-Flocculation of Suspended Matter in Estuaries. Netherlands Journal of Sea Research 1986 20:183-199.

26. Narkis N, Rebhun M: Mechanism of Flocculation Processes in Presence of Humic Substances. Journal American Water Works Association 1975, 67:101-108.

27. Kretzschmar $\mathrm{R}$, Hesterberg $\mathrm{D}$, Sticher $\mathrm{H}$ : Effects of adsorbed humic acid on surface charge and flocculation of kaolinite. Soil Science Society of America Journal 1997, 6 I: 101-108.

28. Tombacz E, Libor Z, Illes E, Majzik A, Klumpp E: The role of reactive surface sites and complexation by humic acids in the interaction of clay mineral and iron oxide particles. In I/th International Conference of the Humic-Substances-Society Boston, MA: Pergamon-Elsevier Science Ltd; 2004.
29. Tombacz E, Szekeres M, Baranyi L, Micheli E: Surface modification of clay minerals by organic polyions. Colloids and Surfaces a-Physicochemical and Engineering Aspects 1998, I 41 1:379-384.

30. Tipping E, Higgins DC: The Effect of Adsorbed Humic Substances on the Colloid Stability of Hematite Particles. Colloids and Surfaces 1982, 5:85-92.

31. Tiller CL, Omelia CR: Natural Organic-Matter and Colloidal Stability - Models and Measurements. In Symp on Colloids in the Aquatic Environment London, England: Elsevier Science Bv; 1992.

32. Tarchitzky J, Chen Y, Banin A: Humic Substances and Ph Effects on Sodium-Montmorillonite and Calcium-Montmorillonite Flocculation and Dispersion. Soil Science Society of America Journal 1993, 57:367-372.

33. Kretzschmar $\mathrm{R}$, Holthoff $\mathrm{H}$, Sticher $\mathrm{H}$ : Influence of $\mathbf{p H}$ and humic acid on coagulation kinetics of kaolinite: A dynamic light scattering study. Journal of Colloid and Interface Science 1998, 202:95-103.

34. Duan SW, Bianchi TS: Seasonal changes in the abundance and composition of plant pigments in particulate organic carbon in the lower Mississippi and Pearl Rivers. Estuaries and Coasts 2006, 29:427-442.

35. Kester DR, Duedall IW, Connors DN, Pytkowic RM: Preparation of Artificial Seawater. Limnology and Oceanography 1967, I2: 176.

36. Berne BJ, Pecora R: Dynamic Ligth Scattering. Malabar, FL: Robert E. Krieger Publishing Company; 1990.

37. Pinheiro JP, Mota AM, dOliveira JMR, Martinho JMG: Dynamic properties of humic matter by dynamic light scattering and voltammetry. Analytica Chimica Acta 1996, 329:15-24.

38. Tombacz E, Filipcsei G, Szekeres M, Gingl Z: Particle aggregation in complex aquatic systems. In International Conference on Interfaces Against Pollution Wageningen, Netherlands: Elsevier Science; 1997.

39. Kaszuba M, McKnight D, Connah MT, McNeil-Watson FK, Nobbmann U: Measuring sub nanometre sizes using dynamic light scattering. Journal of Nanoparticle Research 2008, I 0:823-829.

40. Palmer NE, von Wandruszka R: Dynamic light scattering measurements of particle size development in aqueous humic materials. Fresenius Journal of Analytical Chemistry 2001, 371:951-954.

4I. Baigorri R, Fuentes M, Gonzalez-Gaitano G, Garcia-Mina JM: Analysis of molecular aggregation in humic substances in solution. Colloids and Surfaces A-Physicochemical and Engineering Aspects 2007, 302:301-306.

42. Kim Jl, Buckau G, Li GH, Duschner H, Psarros N: Characterization of Humic and Fulvic-Acids from Gorleben Groundwater. Fresenius Journal of Analytical Chemistry 1990, 338:245-252.

43. Anderson MA, Bertsch PM: Electrophoretic Mobility and Particle-Size of Clays Using Laser-Doppler Velocimetry PhotonCorrelation Spectroscopy. Soil Science Society of America Journal 1993, 57:1641-1643.

44. Muller FLL: Measurement of electrokinetic and size characteristics of estuarine colloids by dynamic light scattering spectroscopy. Analytica Chimica Acta 1996, 33 I:I-15.

45. Kretzschmar R, Robarge WP, Weed SB: Flocculation of Kaolinitic Soil Clays - Effects of Humic Substances and Iron-Oxides. Soil Science Society of America Journal 1993, 57:1277-1283.

46. Majzik A, Tombacz E: Interaction between humic acid and montmorillonite in the presence of calcium ions I. Interfacial and aqueous phase equilibria: Adsorption and complexation. Organic Geochemistry 2007, 38: I 319-1329.

47. Hogg R, Healy TW, Fuersten DW: Mutual Coagulation of Colloidal Dispersions. Transactions of the Faraday Society 1966, 62:1638.

48. Duran JDG, Ramos-Tejada MM, Arroyo FJ, Gonzalez-Caballero F: Rheological and electrokinetic properties of sodium montmorillonite suspensions - I. Rheological properties and interparticle energy of interaction. Journal of Colloid and Interface Science 2000, 229:107-117.

49. Jones JA, Wilkins DK, Smith LJ, Dobson CM: Characterisation of protein unfolding by NMR diffusion measurements. Journal of Biomolecular NMR 1997, 10:199-203. 